\title{
Diabetic Nephropathy in Type 1 (Insulin-Dependent) Diabetes: An Epidemiological Study
}

\author{
A. R. Andersen, J.Sandahl Christiansen, J. K. Andersen, S. Kreiner and T. Deckert \\ Steno Memorial Hospital, Gentofte and Department for Data Processing, Copenhagen County Hospital, Herlev, Denmark
}

Summary. A follow-up of 1475 Type 1 (insulin-dependent) diabetic patients diagnosed before 1953 ( 815 males, $660 \mathrm{fe}-$ males) and before the age of $\mathbf{3 1}$ years was conducted. All patients were seen at the Steno Memorial Hospital and were referred from all parts of Denmark; $91(6 \%)$ could not be traced. The rest $(94 \%)$ were followed until death or for at least 25 years; $249(17 \%)$ were followed for $>40$ years. Clinical diabetic nephropathy developed in 531 (41\%) of the 1303 patients in whom sufficient information was available regarding proteinuria. Other causes of proteinuria were found in $3 \%$, and $57 \%$ did not develop persistent proteinuria. The prevalence of diabetic nephropathy was $21 \%$ after $20-25$ years of diabetes duration followed by a decline to $10 \%$ after 40 years. Two incidence peaks of the onset of proteinuria were seen, one after 16 and another after 32 years duration of diabetes. Incidence increased steeply 10 years after onset of diabetes and was low after 35 years duration. The cumulative incidence was $45 \%$ after 40 years of diabetes. A male preponderance was seen among patients with nephropathy. A significant difference in the pattern of annual incidence rates of diabetic nephropathy was seen, when groups with onset of diabetes before 1933, between 1933-1942, and 1943-1952, respectively, were compared. An association between daily insulin requirement and nephropathy incidence was found. Patients with nephropathy had a much poorer survival than those without proteinuria; 40 years after onset of diabetes, only $10 \%$ of patients who developed nephropathy were alive, whereas $>70 \%$ of patients who did not develop nephropathy survived. Uraemia was the cause of death in $66 \%$ of the patients with nephropathy; 7 years after the onset of persistent proteinuria, $49 \%$ of the patients had died. It is concluded that diabetic nephropathy is the major life threatening complication in Type I diabetes of juvenile onset.

Key words: Type I diabetes, diabetic nephropathy, incidence, prevalence, prognosis.
Nephropathy is a serious complication of Type 1 (insulin-dependent) diabetes mellitus [1] with a grave prognosis after the onset of proteinuria [2-4]. Earlier reports on the course of diabetic nephropathy were based upon heterogeneous series of patients, including patients with both Type 1 diabetes and Type 2 (non-insulin-dependent) diabetes [5-7] or including only Type I diabetic subjects, often representing a rather limited number of patients $[3,8,9]$.

The aim of the present study was to investigate the incidence and prevalence of diabetic nephropathy among patients developing Type 1 diabetes within the first three decades of life. Furthermore, the possible importance of sex, age at onset of diabetes, year of onset, insulin dose, and domicile for the development of diabetic nephropathy was investigated.

\section{Material and Methods}

All patients treated at the Steno Memorial Hospital, in whom juvenile-onset diabetes mellitus (onset before 31 years) was diagnosed be- fore 1953 were included ( $n=1475,815$ males and 660 females). These patients represent about $23 \%$ of all juvenile-onset Type 1 diabetics diagnosed in Denmark between 1923 and 1953. The sex ratio and the distribution of age at onset (Fig. 1) agree with results from incidence studies in Denmark [10] (Table 1).

The patients, who lived in different parts of Denmark ( $40 \%$ in the Copenhagen area, $35 \%$ in cities outside Copenhagen, and $25 \%$ in the countryside) were referred to the Steno Memorial Hospital between 1932 and 1977 for specialist advice on diabetic control. The median duration of disease at the patients' first visit was 7.0 years (range $0-30$ years); 1076 patients ( $73 \%$ ) were referred before 16 years duration of diabetes, and 399 patients after 15 years of diabetes; 165 patients $(11 \%)$ had persistent proteinuria when first seen. Twelve of these had elevated blood urea or serum creatinine. These patients were mainly from the countryside or cities outside Copenhagen; $80 \%$ of the patients received insulin twice daily.

Before the first admission to the Steno Memorial Hospital, many patients had been treated by general practitioners supported by departments of internal medicine. Reports from these departments were included in our observations. After the first admission to the hospital, $60 \%$ of the patients were followed at the Steno Memorial Hospital. The other $40 \%$ were followed by their own practitioner assisted by departments of internal medicine. Reports from hospital and/or practitioners were required in every case. Main causes of death were taken from the death certificate and/or hospital reports. Follow-up until 


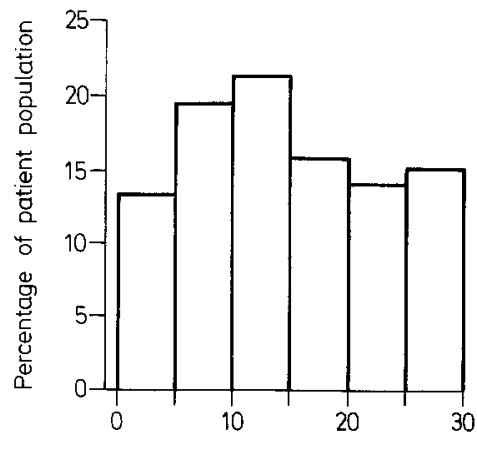

Age at onset of diabetes (years)

Fig. 1. The distribution of age at onset of diabetes in 1475 Type 1 diabetic patients

Table 1. Sex-ratio from a recent representative incidence study of Type 1 diabetes in Denmark [10], the present study of 1475 diabetic patients, and the 531 patients with diabetic nephropathy separately

\begin{tabular}{lccl}
\hline & $\begin{array}{l}\text { Incidence } \\
\text { study [10] }\end{array}$ & $\begin{array}{l}\text { Present } \\
\text { study }\end{array}$ & $\begin{array}{l}\text { Patients with dia- } \\
\text { betic nephropathy } \\
\text { (present study) }\end{array}$ \\
\hline Male/female & $454 / 338$ & $815 / 660$ & $341 / 190$ \\
Male/female & 1.25 & $1.23^{\mathrm{a}}$ & $1.79^{\mathrm{a}}$ \\
\hline
\end{tabular}

${ }^{a}$. $p<0.001$ (Chi-square)

Table 2. Follow-up period of the 1475 patients

\begin{tabular}{lcc}
\hline \multirow{2}{*}{$\begin{array}{l}\text { Time from onset of diabetes } \\
\text { to last follow-up (years) }\end{array}$} & \multicolumn{2}{c}{$\begin{array}{l}\text { Outcome at the end } \\
\text { of the study }\end{array}$} \\
\cline { 2 - 3 } & Alive & Dead \\
\hline $0-4$ & $5^{\mathrm{a}}$ & 11 \\
$5-9$ & $8^{\mathrm{a}}$ & 21 \\
$10-14$ & $10^{\mathrm{a}}$ & 37 \\
$15-19$ & $8^{\mathrm{a}}$ & 108 \\
$20-24$ & $60^{\mathrm{a}}$ & 154 \\
$25-29$ & 180 & 153 \\
$30-34$ & 143 & 112 \\
$35-39$ & 142 & 74 \\
$40-44$ & 141 & 50 \\
$45-49$ & 37 & 15 \\
$50-54$ & 2 & 3 \\
$55-$ & 0 & 1 \\
\hline
\end{tabular}

${ }^{a}$ Follow-up incomplete $(n=91)$

death or for at least 25 years of diabetes was required; 91 patients $(6 \%)$ were lost because of emigration, change of name, etc.; 331 (22\%) died within the first 24 years of diabetes. The follow-up period is further illustrated in Table $2 ; 249$ patients $(17 \%)$ were followed for $>40$ years. The frequency of testing for proteinuria varied considerably. Diabetic nephropathy was defined as persistent proteinuria (protein excretion $>0.5 \mathrm{~g} / 24 \mathrm{~h}$ in at least four consecutive samples of $24 \mathrm{~h}$ urine with an interval of at least 1 month in patients without renal infection. Proteinuria was detected by qualitative examination using Heller's test [11] and, after 1965, by Albustix.

In 172 patients (12\%) (including the 91 patients in whom follow-up was incomplete), the development of proteinuria was questionable (Fig. 2). None of these patients, however, died in uraemia. Except for the absence of death in uraemia, this group of patients did not differ from the rest as regards sex, age at onset or domicile; 35 pat- ients with persistent proteinuria were considered not to have diabetic nephropathy (Fig. 2), since chronic urinary tract infections or glomerulonephritis were diagnosed. These patients were therefore excluded from the incidence study, but included in the data of survival. In this retrospective study, renal biopsy was only performed in a few cases.

In 380 cases, the onset of persistent proteinuria could be determined fairly accurately, the maximal time between the last negative test for protein and the beginning of persistent proteinuria being 5 years (mean \pm SD: $1.4 \pm 1.4$ years). In a further 151 patients, the onset of proteinuria could not be determined accurately since regular tests for protein excretion were not performed throughout the whole course of diabetes. The mean \pm SD interval between the last period without persistent proteinuria and the period with persistent proteinuria was $17 \pm 6$ years. Incidence, prevalence, and survival after onset of proteinuria were calculated only on the basis of the 380 cases of nephropathy ( $72 \%)$, where onset could be determined accurately. A randomly selected population of patients without nephropathy served as controls (Fig. 2). The other $28 \%$ did not differ significantly from the selected group regarding sex, age at onset or domicile.

Sex and age at diagnosis of diabetes were registered. The prevalent domicile, adult body weight in percentage of ideal body weight [12], adult body height, and adult insulin dose $/ \mathrm{kg}$ body weight in nonpregnant diabetic patients $>2$ years of duration with normal serum creatinine were recorded in most cases. Also the domicile of the patients and the length of the period from onset of diabetes until the first referral to the Steno Memorial Hospital were registered.

\section{Statistical Analysis}

Chi-square test and Markov chain models (log-linear/logistic) were used for statistical analysis [13].

\section{Results}

The 1303 patients with Type 1 diabetes for whom there was sufficient information on proteinuria were followed until death or for at least 25 years after the onset of diabetes (Fig. 2); 531 patients (41\%) developed diabetic nephropathy, $35(3 \%)$ persistent proteinuria from causes other than diabetes, and $737(57 \%)$ did not develop persistent proteinuria during follow-up. The prevalence of nephropathy in relation to duration of diabetes is shown in Figure 3. The maximal prevalence $(21 \%)$ was seen after $20-25$ years of diabetes, whereafter it declined to about $10 \%$ in patients who had suffered from diabetes for 40 years or more. Only $4 \%$ developed nephropathy before 10 years duration of diabetes.

The annual incidence of diabetic nephropathy (new cases per year) is seen in Figure 4. There seem to be two peaks, one after 16 years and a smaller one after 32 years. The incidence at 32 years is significantly higher $(p<0.05)$ than at 31 and 33 years. The incidence rate declines to about $1 \%$ in patients who had suffered from diabetes for 40 years or more. Patients surviving 35 years of diabetes seem to be at low risk for the development of diabetic nephropathy, since only $4 \%$ developed it more than 35 years after diagnosis of diabetes.

The cumulative incidence (Fig. 5) indicates clearly that only about $45-50 \%$ of juvenile diabetic patients will ever develop nephropathy. Enviromental factors seem to influence the incidence of nephropathy. Thus, a 


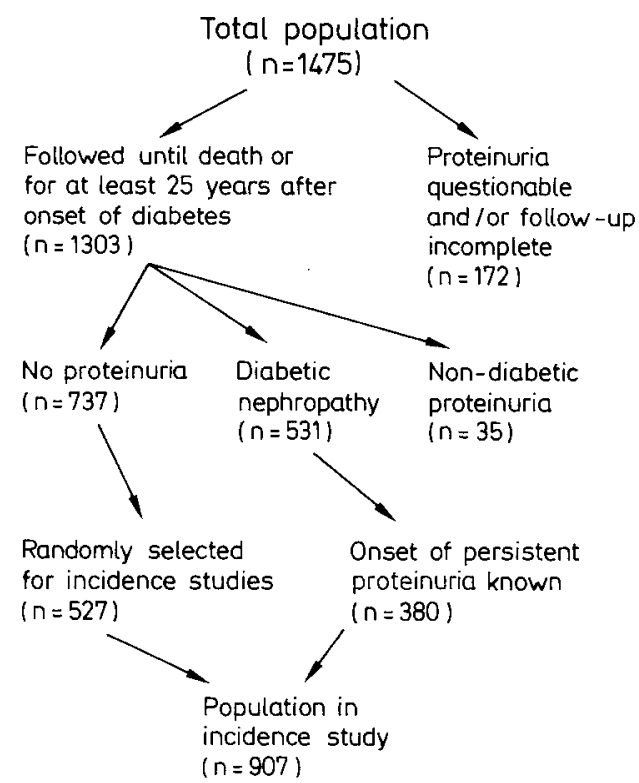

Fig. 2. The subdivision of the cohort of 1475 Type 1 diabetic patients. (See text for details)

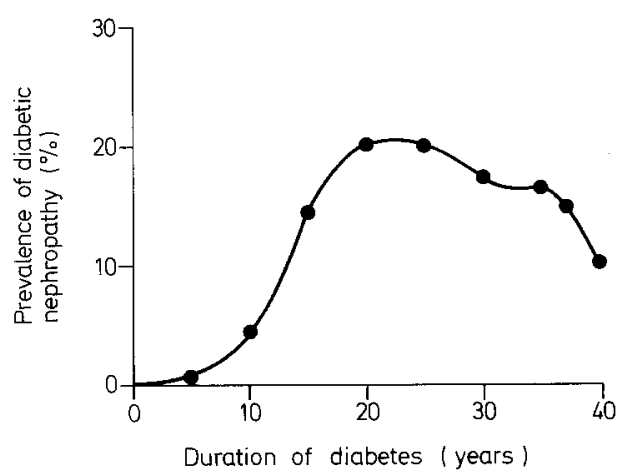

Fig. 3. Prevalence of diabetic nephropathy in relation to duration of diabetes in the 907 Type 1 diabetic patients selected for incidence and prevalence studies

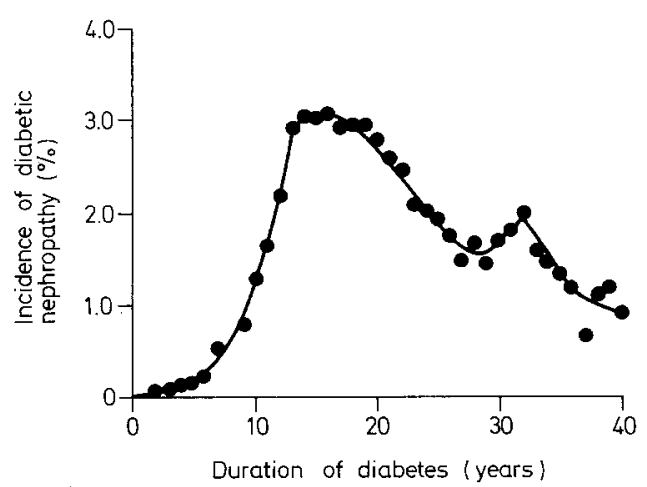

Fig.4. Incidence (annual new cases) of diabetic nephropathy in relation to duration of diabetes in the 907 Type 1 diabetic patients selected for incidence and prevalence studies significant difference in the pattern of annual incidence rates of nephropathy was seen, when groups with onset of diabetes before 1933, between 1933-1942, and 1943-1952, respectively, were compared ( $p<0.00005$; Table 3). A peak of incidence of diabetic nephropathy was found between 1950 and 1960 . Sex seems to play a role, as the risk was significantly higher in men than in women $(p<0.001$; Table 1$)$. The higher incidence of nephropathy among men was found especially in patients with late onset of proteinuria (Table 4).

The male preponderance was independent of age at onset of diabetes. In general, age at onset of diabetes was of no importance for the incidence of nephropathy, since no association was found between low age at onset and incidence of nephropathy $(p=0.081$; Table 5).

The 24-h insulin dose/ $\mathrm{kg}$ body weight was significantly higher in patients developing nephropathy compared with those who did not $(p=0.012)$. The incidence of diabetic nephropathy was also significantly higher among patients from rural districts compared with those from built-up areas ( $p=0.0066$, Table 6$)$.

Percentage of ideal body weight was not different when patients with and without nephropathy were compared $(94.7 \pm 8.8 \%$ versus $93.8 \pm 9.2 \%$ in males and $98.4 \pm 9.6 \%$ versus $96.4 \pm 9.4 \%$ in females). Patients with longer delay between onset of diabetes and first visit to the Steno Memorial Hospital did not show more nephropathy than patients referred during the first 2 years of diabetes.

Four-hundred and forty-one out of 531 patients with nephropathy had died by the end of the follow-up period $(83 \%)$ compared with only 186 of $737(25 \%)$ of patients without proteinuria.

In the group with nephropathy, $66 \%$ died primarily from uraemia, $19 \%$ from ischeamic heart disease or strokes $(5 \%)$, all having elevated serum creatinine ( $>150 \mu \mathrm{mol} / 1)$. Patients with early onset nephropathy, i.e. those who developed persistent proteinuria during the first 20 years of diabetes, died more often from uraemia, whereas patients who developed persistent proteinuria after $>20$ years of diabetes died mainly from ischaemic heart disease $(77 \%$ and $46 \%$ respectively from uraemia, $11 \%$ and $41 \%$ respectively from ischaemic heart disease). Death from ketoacidosis was more frequent among patients without nephropathy, probably since this group included all patients who died after only a few years of diabetes. Furthermore, the percentage of deaths from infectious diseases was higher among patients without proteinuria because this group included several patients who died from tuberculosis after a few years of diabetes. The survival is demonstrated in Figure 6, which shows patients with nephropathy (including those with persistent proteinuria from other renal diseases) to have a much poorer survival than patients who do not develop nephropathy.

Survival after the onset of persistent proteinuria was poor. Figure 7 shows the cumulative number of deaths with the duration of persistent proteinuria. After 


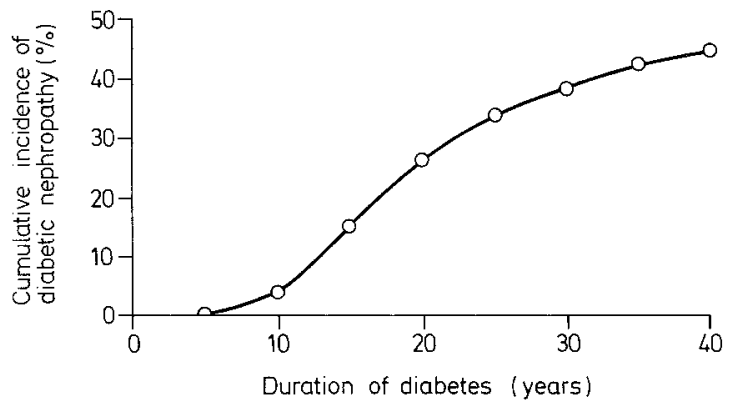

Fig.5. Calculated cumulative incidence of diabetic nephropathy in relation to duration of diabetes in the 907 Type 1 diabetic patients selected for incidence and prevalence studies

Table 3. Incidence of diabetic nephropathy in relation to year of diagnosis

\begin{tabular}{llll}
\hline \multirow{2}{*}{$\begin{array}{l}\text { Years after onset } \\
\text { of diabetes }\end{array}$} & \multicolumn{2}{l}{\begin{tabular}{l} 
Incidence of diabetic nephropathy (\%/year) \\
\cline { 2 - 4 }
\end{tabular}} & \multicolumn{2}{l}{ Diabetes onset } \\
\cline { 2 - 4 } & Before $1933^{\mathrm{a}}$ & $1933-1942^{\mathrm{b}}$ & $1943-1952^{\mathrm{c}}$ \\
\hline $0-5$ & 0.00 & 0.14 & 0.00 \\
$6-8$ & 0.00 & 0.68 & 0.38 \\
$9-11$ & 0.37 & 0.91 & 1.46 \\
$12-20$ & 2.43 & 3.60 & 2.91 \\
$21-25$ & 3.12 & 2.78 & 1.02 \\
$26-35$ & 2.32 & 0.87 & \\
$36-$ & 1.22 & 0.98 & \\
\hline
\end{tabular}

$a, b, c$ Comparison of incidence patterns by Markov chain analysis showed highly significant differences $(p<0.00005)$

Table 4. Incidence of diabetic nephropathy in relation to duration of diabetes and sex

\begin{tabular}{lll}
\hline $\begin{array}{l}\text { Duration of } \\
\text { diabetes (years) }\end{array}$ & \multicolumn{2}{l}{$\begin{array}{l}\text { Incidence of diabetic nephropathy } \\
\text { (\%/year) }\end{array}$} \\
\cline { 2 - 3 } & Women & Men \\
\hline 3 & 0.04 & 0.07 \\
7 & 0.42 & 0.41 \\
9 & 1.03 & 1.07 \\
16 & 2.76 & 3.37 \\
23 & 1.53 & 2.70 \\
30 & 0.86 & 2.49 \\
40 & 0.59 & 1.58 \\
\hline
\end{tabular}

( $p<0.0001$; Markov chain analysis)

Table 5. Cumulative percentage incidence of diabetic nephropathy in relation to duration and age at diagnosis

\begin{tabular}{lllll}
\hline \multirow{2}{*}{$\begin{array}{l}\text { Age at onset of } \\
\text { diabetes (years) }\end{array}$} & \multicolumn{4}{l}{ Incidence of diabetic nephropathy (\%) } \\
\cline { 2 - 5 } & \multicolumn{4}{c}{ Diabetes duration (years) } \\
\cline { 2 - 5 } & 5 & 15 & 25 & 35 \\
\hline $0-10$ & 4.8 & 15.7 & 35.7 & 43.9 \\
$11-20$ & 4.7 & 15.1 & 33.2 & 42.0 \\
$21-30$ & 4.7 & 15.3 & 33.9 & 42.1 \\
\hline
\end{tabular}

7 years, $49 \%$ of the patients have died independent of sex and age at onset of diabetes. The time from onset of proteinuria to death varied from 1 to 24 years. However, the cause of death in the rapidly progressive cases (i.e. patients who died 1-9 years after the onset of proteinuria) was similar to the cause of death in patients who died $>10$ years after the onset of proteinuria $(64 \%$ and $66 \%$ respectively from uraemia, both groups showing $19 \%$ for ischaemic heart disease).

\section{Discussion}

The present study comprises patients with onset of diabetes before 1953 and aged below 31 years at diagnosis. This group seems to be fairly well-defined with a welldocumented onset of the disease. It is also representative of diabetic patients of a similar age in Denmark generally (Table 1).

Since 165 patients had persistent proteinuria at the first visit to the hospital, it could be argued that there has been selection of patients with proteinuria. However, nearly all patients were referred to the hospital because of poor metabolic control and not because of subjective symptoms of complications, such as blindness, foot ulcers or uraemia. We cannot exclude the possibility that proteinuria at a young age was a contributing factor for the referral to us. Since, however, the incidence of proteinuria was not significantly different in diabetics referred to the hospital after $0-2,2-13$, and $\geqslant 13$ years of diabetes ( $p=0.55)$, our prevalence and incidence figures may be regarded as representative.

The diagnosis of diabetic nephropathy was based on generally accepted clinical criteria since renal biopsies were not available in this material.

The study revealed that $41 \%$ of the patients developed nephropathy and that the calculated cumulative incidence of nephropathy after 40 years of diabetes was $45 \%$ (Fig. 5), in agreement with earlier studies [14]. The prevalence rose steeply to a maximum of $21 \%$ after 20 years of diabetes duration, and thereafter fell slowly to $10.5 \%$ after 40 years (Fig. 3 ).

Surprisingly, there seem to be two incidence peaks, one after 16 and another after 32 years duration of diabetes. This might reflect heterogeneity of diabetic nephropathy, but so far we have not been able to characterize further early and late onset nephropathy.

The following factors seem to be of importance for the prevalence and/or incidence of diabetic nephropathy: sex, calendar year, domicile and insulin dose $/ \mathrm{kg}$ body weight, whereas age at onset and the delay between onset of diabetes and first visit to a specialized medical unit do not seem to be of importance.

Male preponderance is also seen in patients with other kidney diseases, such as Goodpasture's syndrome and glomerulonephritis [15]. Why it occurs in patients with diabetic nephropathy is unknown. However, men 
Table 6. Incidence of diabetic nephropathy in relation to domicile

\begin{tabular}{|c|c|c|c|}
\hline \multirow{2}{*}{$\begin{array}{l}\text { Years after } \\
\text { onset of diabetes }\end{array}$} & \multicolumn{3}{|c|}{ Incidence of diabetic nephropathy ( $\% /$ year) } \\
\hline & $\begin{array}{l}\text { Copenhagen } \\
\text { area }^{\mathrm{a}}\end{array}$ & $\begin{array}{l}\text { Cities outside } \\
\text { Copenhagen }^{b}\end{array}$ & $\begin{array}{l}\text { Rural } \\
\text { areas }^{c}\end{array}$ \\
\hline $0-5$ & 0.00 & 0.12 & 0.08 \\
\hline $6-8$ & 0.10 & 0.63 & 0.83 \\
\hline $7-11$ & 0.69 & 1.45 & 1.41 \\
\hline $12-20$ & 2.82 & 3.23 & 4.52 \\
\hline $21-25$ & 1.96 & 1.55 & 3.08 \\
\hline $26-35$ & 1.47 & 1.68 & 0.66 \\
\hline $36-$ & 0.91 & 1.23 & 0.94 \\
\hline
\end{tabular}

A significantly higher incidence rate was found in ${ }^{c}$ compared with ${ }^{\mathrm{a}}$ and ${ }^{\mathrm{b}}(p=0.0066$; Markov chain analysis)

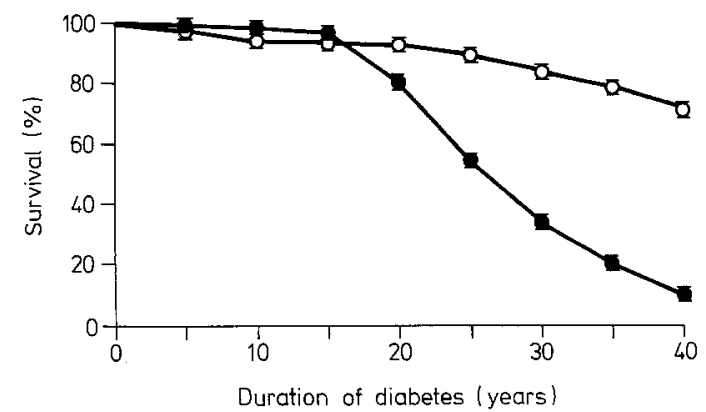

Fig. 6. Survival of Type 1 diabetic patients with $\left(n=566.0_{-}\right)$and without ( $n=737$ ) nephropathy in relation to duration of diabetes (mean $\pm \mathrm{SD}$ )

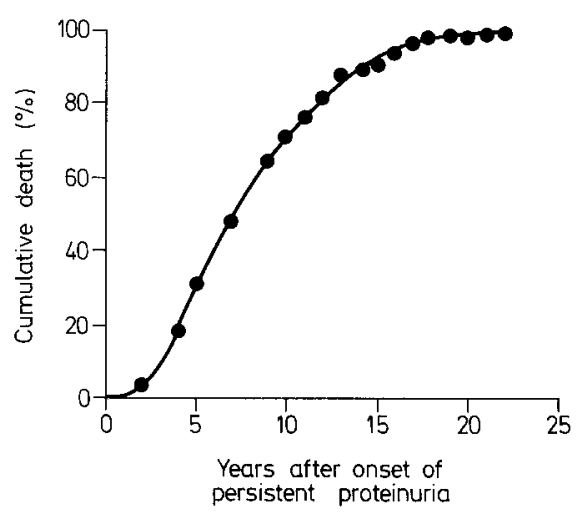

Fig. 7. Cumulative death in patients dying with diabetic nephropathy $(n=360)$ in relation to duration of persistent proteinuria

are heavier smokers than women, and diabetic nephropathy has been shown to be significantly more frequent in cigarette smokers [16].

The possible influence of calendar years on the incidence of diabetic nephropathy is interesting (Table 3). This tendency has also been observed in cohort studies from the Joslin Clinic, where the cohort diagnosed in 1949 had a significantly reduced incidence of nephropathy compared with the cohort of patients with onset in 1939 (J.H. Warram, personal communication). This might point to the importance of environmental factors although we have no idea of the nature of this factor or factors.

The importance of domicile, i.e. that patients living in rural districts have a higher incidence of nephropathy, might be explained by less medical supervision (worse control) of patients living in rural districts compared to patients living in the Copenhagen area. Environmental factors predominantly present in rural districts also might explain the difference. However, it cannot be excluded that early development of complications in some cases contributed to the practitioner's decision to refer the patient to a specialist diabetic department.

Insulin requirements seem to be higher amongst patients later developing nephropathy compared to those who do not. This could be due to higher levels of insulin antibodies. However, no correlation between insulin antibodies and nephropathy has been found [17]. A good correlation has been shown between the daily insulin dose/ $\mathrm{kg}$ body weight and glucagon-induced Cpeptide response [18]. The high insulin dose in nephropathy might indicate less persisting endogenous insulin production. Long-term Type I diabetic patients without persisting endogenous insulin secretion have significantly more proliferative retinopathy and/or nephropathy than comparable long-term Type I diabetic subjects with persisting C-peptide response [18]. Another explanation could be the higher consumption of cigarettes in the nephropathy groups [16], since cigarette smoking Type I diabetic patients have a higher insulin requirement $/ \mathrm{kg}$ body weight [19].

Good metabolic control seems to have a significant beneficial effect upon the survival in a large sample of Type I diabetic patients of juvenile onset [1]. The present study does not give good evidence for the importance of good metabolic control in the prevention of nephropathy. On the other hand, Pirart has shown that good control of diabetes seems to protect against the development of nephropathy [5]. However, the patient population in his study was rather heterogeneous.

Our study shows convincingly that diabetic nephropathy is a very severe complication of Type I diabetes and that survival after the onset of proteinuria is poor. However, the range of survival after the onset of proteinuria is wide (1-24 years) which agrees with other observations [20]. If nephropathy appears in patients with early onset of diabetes the course does not seem to be worse than nephropathy appearing in patients with late onset of diabetes [4]. Our studies demonstrate that proteinuria does not start earlier in patients with early onset of diabetes.

The main cause of death among patients with diabetic nephropathy was uraemia $(66 \%)$, which is a little higher than found in other studies [21]. It has recently been shown that early aggressive antihypertensive treatment is able to postpone the onset of uraemia in these patients [22], but prevention of nephropathy is neces- 
sary if the prognosis of Type I diabetes has to be changed radically.

Acknowledgements. This study was supported by grants from Landsforeningen for Sukkersyge, Nordisk Insulinlaboratorium, Løvens Kemiske Fabrik, and the Weimann Legacy. The secretarial assistance of Mrs. J.Hvalsøe Olsen and Mrs. A.Jerichow is gratefully acknowledged.

\section{References}

1. Deckert T, Poulsen JE, Larsen M (1978) Prognosis of diabetics with diabetes onset before the age of thirty-one. Diabetologia 14: 363-377

2. Wilson JL, Root HF, Marble A (1951) Diabetic nephropathy. A clinical syndrome. N Engl J Med 245: 513-517

3. Kussman JM, Goldstein HH, Gleason RE (1976) The clinical course of diabetic nephropathy. JAMA 236: 1861-1863

4. Andersen AR, Andersen JK, Christiansen JS, Deckert T (1978) Prognosis for juvenile diabetics with nephropathy and failing renal function. Acta Med Scand 203: 131-134

5. Pirart J (1977) Diabetes mellitus and its degenerative complications: a prospective study of 4400 patients observed between 1947 and 1973. Diabet Metab 3: 97-107, 174-182, 245-256

6. Thomsen AC (1965) The kidney in diabetes mellitus. Ph D Thesis, Munksgaard, Copenhagen

7. Entmacher PS, Root H, Marks HH (1964) Longevity of diabetic patients in recent years. Diabetes 13:373-377

8. Watkins PJ, Blainey JD, Brewer DB, et al (1972) The natural history of diabetic renal disease: a follow-up study of a series of renal biopsies. Q J Med 41: 437-456

9. Balodimos MC (1971) Diabetic nephropathy. In: Marble A, White P, Bradley RF, Krall LP (eds) Joslin's diabetes mellitus, 11th ed. Lea and Febiger, Philadelphia, pp 526-528

10. Christau B, Kromann H, Christy M, Andersen OO, Nerup J (1979) Incidence of insulin-dependent diabetes mellitus $(0-29$ years at onset) in Denmark. Acta Med Scand [Suppl] 624: 54-60
11. Astrup P, Brøchner Mortensen K, Faber M (1959) Clinical laboratory techniques. August Bang, Copenhagen

12. Natvig H (1956) New height and weight tables for Norwegian women and men. Landsforeningen for kosthold og helse, Oslo

13. Bishop YMM, Fienberg SE, Molland PW (1971) Discrete multivariate analysis. Theory and practice. M I T Press, Cambridge, MA, London, UK, pp 257-280

14. White $P(1956)$ Natural course and prognosis of juvenile diabetes. Diabetes 5: 445-450

15. Finn R, Morner D (1979) Aetiological implications of sexratio in glomerulonephritis. Lancet 2: 1194

16. Christiansen JS (1978) Cigarette smoking and prevalence of microangiopathy in juvenile-onset insulin dependent diabetes mellitus. Diabet Care 1: 146-149

17. Ortved Andersen $O(1976)$ Anti-insulin antibodies and late diabetic complications. Acta Endocrinol $83: 329-340$

18. Eff C, Faber O, Deckert T (1978) Persistent insulin secretion, assessed by plasma $\mathrm{C}$-peptide estimation in long-term juvenile diabetics with a low insulin requirement. Diabetologia 15:169-172

19. Madsbad S, McNair P, Christensen MS, Christiansen C, Faber OK, Binder C, Transbøl I (1980) Influence of smoking on insulin requirement and metabolic status in diabetes mellitus. Diabetes Care 3: 41-43

20. Knowles HC (1971) Long-term juvenile diabetes treated with unmeasured diet. Trans Assoc Am Physicians 84: 95-100

21. Marks HH, Krall LP (1971) Onset, prognosis, and morbidity in diabetes mellitus. In: Marble A, White P, Bradley RF, Krall LP (eds) Joslin's diabetes mellitus, 11th ed. Lea and Febiger, Philadelphia, pp 209-254

22. Parving H-H, Andersen AR, Smidt UM, Svendsen PA (1983) Early aggressive antihypertensive treatment reduces rate of decline in kidney function in diabetic nephropathy. Lancet 1 : 1175-1180

Received: 21 December 1982

and in revised form: 27 June 1983

Dr. J.Sandahl Christiansen

Steno Memorial Hospital

DK-2820 Gentofte

Denmark 